\title{
ResearchArticle
}

\section{Identification of candidate markers associated with frying colour trait of potato}

\author{
PUNAM GHARGE AND I.R.H.J. (HERMAN) VAN ECK
}

\begin{abstract}
SUMMARY
The demand for potato products like chips and French fries is steadily increasing all over the world. Consumers and potato processing industries have become more stringent for quality along with higher demand of products. Hence, potato breeders are stimulated to develop new potato cultivars with more emphasis on quality traits. Potato breeding is mainly based on crossing two heterozygous parents or complementary parental clones and multi-year clonal selection to identify candidate cultivars with excellent quality. Hence, modern breeders like to use DNA/molecular markers to speed up the selection process by screening large numbers of genotypes at a time. To end up with a shortlist of candidate markers, three criteria; consistency, redundancy and multiple testing corrections were used for removal of false positive and redundant associations. In total, 62 marker-trait associations for frying colour were found to be informative after consistency over several sub traits with threshold level $>3.3$ in at least three sub traits. Finally, replacement analysis was performed to replace unmapped markers with mapped markers. 22 markers for frying colour trait were selected as a set of marker which could be used in Marker assisted breeding. It is clear that statistical approach provides a quick way of analyzing vast amounts of marker-trait associations to end up with short list of candidate markers. However, conformation is still needed to validate the markers.
\end{abstract}

Key Words : Potato, Candidate markers, Marker assisted selection, Marker-trait associations, Frying colour etc.

How to cite this article : Gharge, Punam and Van Eck, I.R.H.J. (Herman) (2016). Identification of candidate markers associated with frying colour trait of potato. Internat. J. Plant Sci., 11 (2): 291-298, DOI: 10.15740/HAS/IJPS/11.2/291-298.

Article chronicle : Received : 13.03.2016; Revised : 10.05.2016; Accepted : 16.06.2016

MEMBERS OF THE RESEARCH FORUM

Author to be contacted :

PUNAM GHARGE, Department of Agricultural Botany, College of Agriculture (M.P.K.V.) BARAMATI (M.S.) INDIA

Address of the Co-authors:

I.R. H.J. (HERMAN) VAN ECK, Laboratory of Plant Breeding, Plant Sciences Group, Wageningen University and Research Center, NETHERLANDS 